\title{
A Hermetic Glass-Silicon Package Formed Using Localized Aluminum/Silicon-Glass Bonding
}

\author{
Yu-Ting Cheng, Liwei Lin, and Khalil Najafi, Fellow, IEEE
}

\begin{abstract}
A hermetic package based on localized aluminum/silicon-to-glass bonding has been successfully demonstrated. Less than 0.2 MPa contact pressure with $46 \mathrm{~mA}$ current input for two parallel 3.5- $\mu \mathrm{m}$-wide polysilicon on-chip microheaters can raise the temperature of the bonding region to $700{ }^{\circ} \mathrm{C}$ bonding temperature and achieve a strong and reliable bond in $\mathbf{7 . 5}$ min. The formation of aluminum oxide with silicon precipitate composite layer is believed to be the source of the strong bond. Accelerated testing in an autoclave shows some packages survive more than $450 \mathrm{~h}$ under $3 \mathrm{~atm}, 100 \% \mathrm{RH}$ and $128{ }^{\circ} \mathrm{C}$. Premature failure has been attributed to some unbonded regions on the failed samples. The bonding yield and reliability have been improved by increasing bonding time and applied pressure.

[594]
\end{abstract}

Index Terms-Activiation energy, aluminum/(silicon)-glass bonding, Hermetic MEMS package, localized heating, reliability.

\section{INTRODUCTION}

H ERMETIC packaging is important for integrated circuit (IC) and MEMS applications. The package should protect devices not only from the hostile external environments for long lifetime, but also from contaminants for better performance [1]-[3]. In the past few years, several approaches have been proposed for the fabrication of a hermetic seal [4]-[7]. In these approaches, a common method to encapsulate MEMS devices utilizes capsules that are bonded to a MEMS substrate. This kind of post-packaging approach provides low cost and flexible process design. However, in order to achieve a good bond many of these techniques require a high temperature, which is incompatible with low temperature needed to reduce thermal impact on the package and substrate. Previously, we reported various types of localized bonding schemes, including eutectic and fusion [8], intermediate layer soldering [9], and CVD bonding [10]. All of these bonding techniques have demonstrated a high quality bond needed for packaging without exposing the MEMS devices to a high-temperature environment.

Manuscript received July 7, 2000; revised January 30, 2001. This work was supported in part by the DARPA ETO/MEMS program under Contract F30602-97-2-0101. The work of L. Lin was supported in part by an NSF CAREER Award (ECS-9734421). Subject Editor G. Stemme.

Y.-T. Cheng was with the Center for Wireless Integrated Microsystems, Department of Electrical Engineering and Computer Science, The University of Michigan, Ann Arbor, MI 48109 USA. He is now with IBM Thomas J. Watson Research Center, Yorktown Heights, NY 10598 USA (e-mail: yuting@us.ibm.com).

K. Najafi is with the Center for Wireless Integrated Microsystems, Department of Electrical Engineering and Computer Science, The University of Michigan, Ann Arbor, MI 48109 USA.

L. Lin is with the Berkeley Sensor and Actuator Center, Department of Mechanical Engineering, University of California at Berkeley, Berkeley, CA 94720 USA.

Publisher Item Identifier S 1057-7157(01)05635-9.
In many hermetic packaging technologies, glass is generally chosen as a protection cap for hermetic packaging because it is mechanically robust, chemically stable, and transparent to light and RF signals which is desirable for biological or optical MEMS applications [11], [12]. Metal solder joints have been employed for IC or MEMS packaging [13], [14] and generally provide lower permeability to moisture than materials like glass, epoxy or silicon. With a width of $1 \mu \mathrm{m}$, metal can effectively block moisture for over 10 years [15]. Although we have already demonstrated glass-to-silicon bonding using localized heating and bonding via indium solder, the weak mechanical strength of indium has made it inappropriate for some micropackaging applications. Previously, aluminum has been shown to react with amorphous oxide [16], vitreous silica [17], and thermal dioxide [17]-[19]. In this paper, we present a new packaging scheme based on aluminum-to-glass bonding using the localized heating technique, apply this technique to the development of a hermetic package for MEMS, and present test results and techniques to improve the reliability and hermeticity of the package. Because aluminum is a complementary metal-oxide-semiconductor (CMOS) compatible material and has superior mechanical properties, it is our belief that this hermetic package will be very useful in other MEMS and IC applications.

\section{STRUCTURE AND FABRICATION}

Fig. 1(a) shows the schematic diagram of the hermetic package based on localized aluminum/silicon-to-glass bonding. The structure consists of polysilicon interconnection lines, which transfer signals from the sealed cavity of the package to the outside world, an on-chip resistive polysilicon microheater, which provides thermal energy for the bonding, and the bonding material, which in this case is aluminum/silicon. The fabrication process follows our previous report on localized solder bonding with a built-in aluminum-based dew point sensor [9]. After forming the polysilicon interconnection line and microheater, an oxide $(1000 \AA) /$ nitride $(500 \AA) /$ oxide $(1000 \AA)$ sandwich layer is deposited on top of a polysilicon microheater for electrical insulation. Because the bonding temperature of aluminum/silicon-to-glass bond is above $600{ }^{\circ} \mathrm{C}$, using the sandwich dielectric layer can effectively prevent aluminum solder from diffusing into the microheater and generating electrical leakage paths during the formation of strong aluminum/silicon-to-glass bond for packaging. After depositing the dielectric layer, a $5000 \AA$ polysilicon adhesion layer and a $2-\mu \mathrm{m}$-thick aluminum layer are deposited and patterned. 


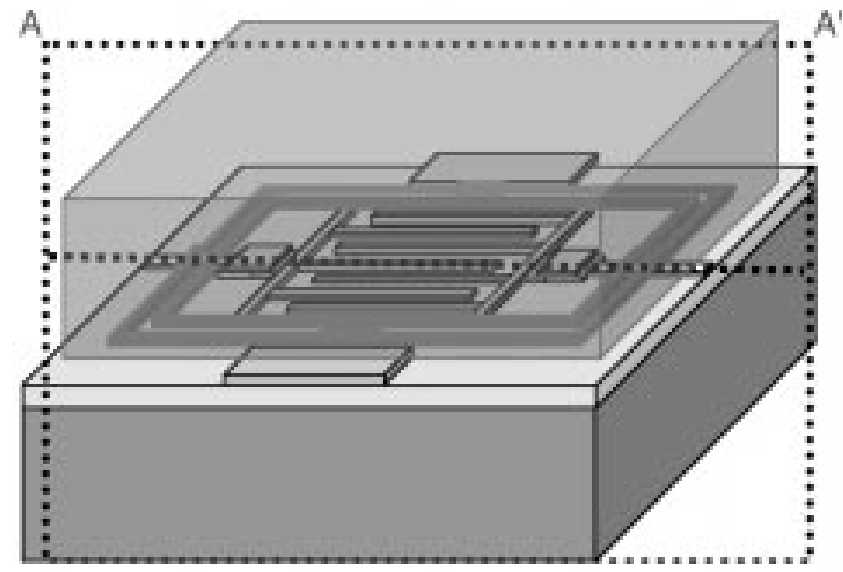

Cross Sectional View Along AA' plane

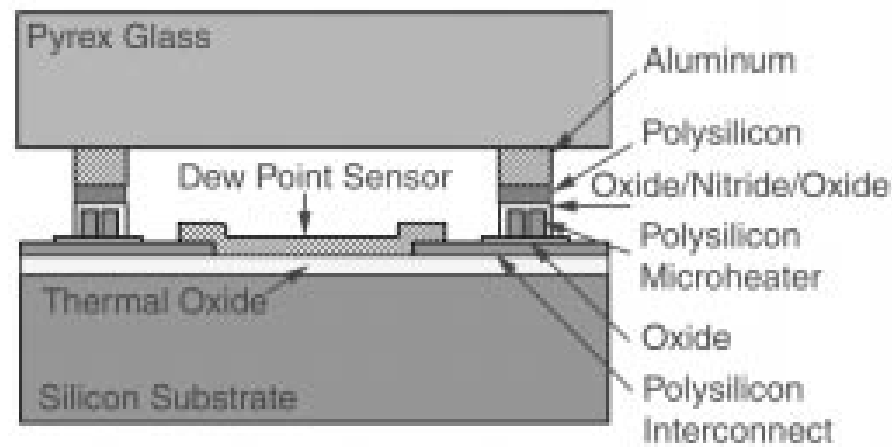

(a)

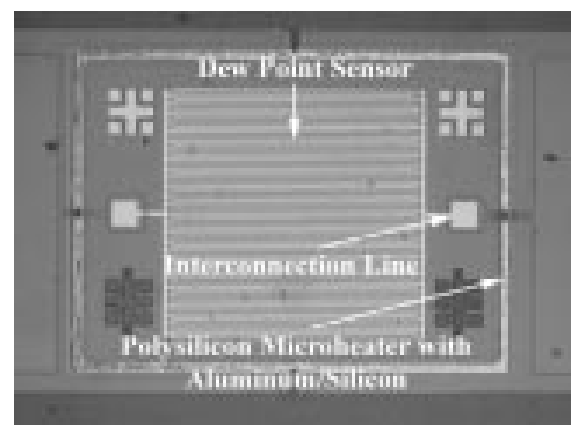

(b)

Fig. 1. Schematic diagram of the hermetic package fabricated by localized aluminum/silicon-to-glass bonding (a) cross section of the package and (b) optical photograph of the hermetic package seen through the glass capsule.

To perform the bonding, a pyrex glass capsule is placed on top of the device substrate. Bonding is achieved under an applied pressure of $0.1 \mathrm{MPa}$ and a current input of $46 \mathrm{~mA}$. The applied pressure is calculated by dividing the applied force by the actual contact area which is equal to the top surface area of the polysilicon microheater. The applied force is measured from the force sensor underneath the package sample [8]. The 46-mA-current input can make the temperature of the microheater designed as two parallel $3.5-\mu \mathrm{m}$-wide, $2-\mu \mathrm{m}$-thick phosphorus-doped polysilicon lines with $7.5 \times 10^{19} / \mathrm{cm}^{3}$ dopant concentration and $2 \mu \mathrm{m}$ spacing rise to $700{ }^{\circ} \mathrm{C}$. In about $5 \mathrm{~min}$, the localized aluminum/silicon-to-glass bonding is completed. Fig. 1(b) shows an optical micrograph of a sealed dew point sensor observed through the glass package.

Bonding temperature is controlled by the microheater whose temperature is monitored by assuming a linear dependence of resistivity with respect to temperature [8]. Fig. 2 shows a twodimensional (2-D) heat transfer simulation of the package by using finite element analysis (FEA). The simulation result indicates two important features. First, the heating region extends laterally along the polysilicon interconnect line due to the larger thermal conductivity of polysilicon than silicon dioxide. However, most of the heating region is still locally confined and the silicon substrate is still kept at low temperature. Second, the temperature of aluminum/(silicon) solder is about $90 \%$ of the

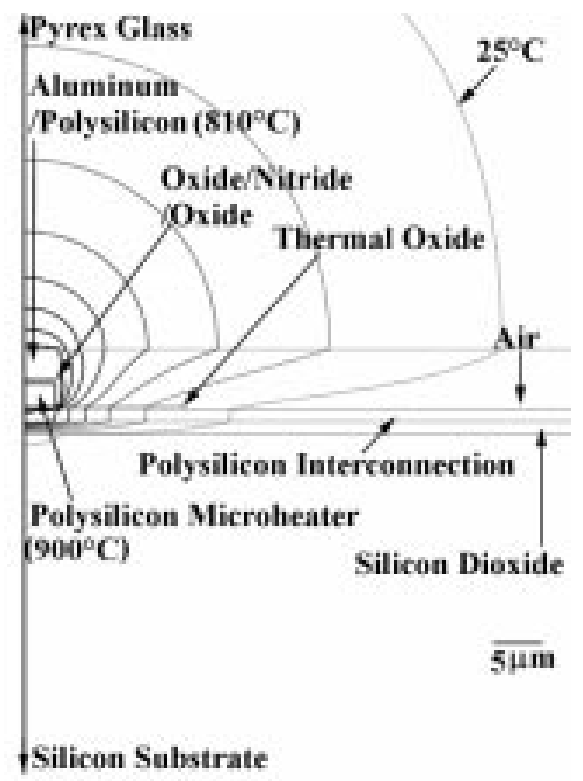

Fig. 2. A 2-D heat transfer simulation of the package by using FEA.

microheater temperature due to the heat conduction loss to the electrical insulation layer. 


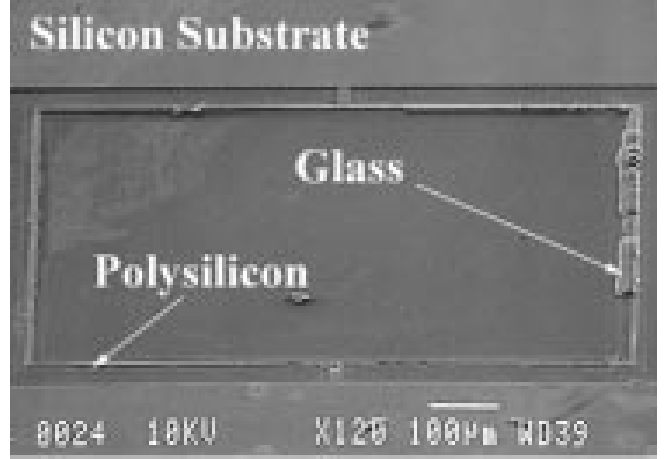

(a)

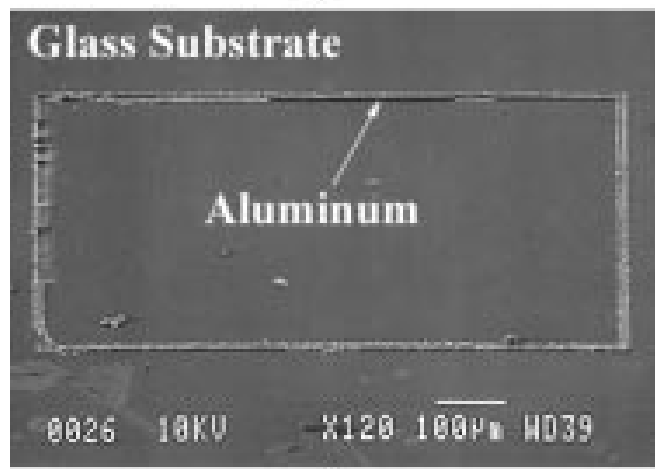

(b)

Fig. 3. SEM micrographs of localized aluminum-glass bonding interface after forcefully broken (a) glass is torn apart and transferred onto the microheater in the silicon substrate (b) aluminum film is most stripped from the silicon substrate then transferred into the glass substrate.

\section{FABRICATION RESULTS}

\section{A. Localized Aluminum/(Silicon)-Glass Bonding}

The aluminum-to-glass bonding is characterized by using a design similar to the hermetic package but without a polysilicon adhesion layer, electrical interconnections and a dew point sensor. Fig. 3 shows the broken interface of localized aluminum-glass bond formed at $\sim 775^{\circ} \mathrm{C}$ in 3 min by passing an input current of $50 \mathrm{~mA}$ through the microheater. Glass debris can be found on the silicon substrate as shown in Fig. 3(a) and some of the aluminum structure is detached from the silicon substrate and attached to the Pyrex-glass as observed in Fig. 3(b). This demonstrates that the aluminum-glass bond is as strong as the aluminum to oxide bond formed underneath the aluminum.

In this experiment, it was found that the stress between as-deposited aluminum film and its underneath oxide is quite high. When aluminum thickness increases over $2 \mu \mathrm{m}$, it delaminates from the underlying oxide. In order to solve this problem, a polysilicon adhesion layer is inserted between aluminum and oxide. Very similar bonding characteristics can be found in the aluminum/silicon-glass bonding structure with a major observable difference that the broken interface generally happens at the microheater and its underneath thermal oxide layer. Fig. 4(a) is the enlarged view of Fig. 3(b) showing the aluminum line is attached to the glass substrate. Fig. 4(b) is the comparative result from the aluminum/silicon-glass bond showing the whole polysilicon microheater is transferred onto the glass substrate.

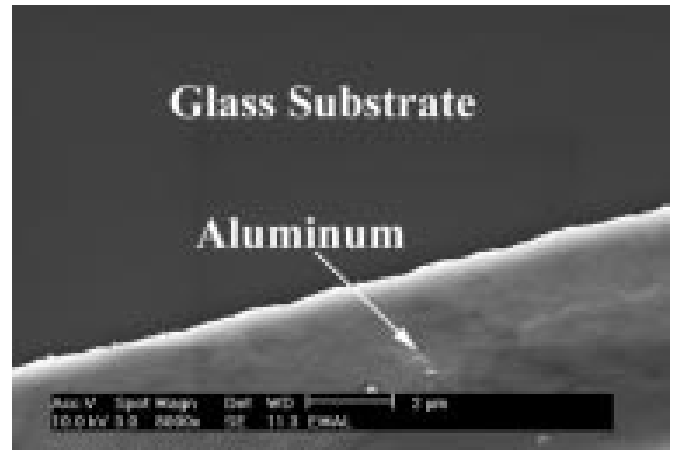

(a)

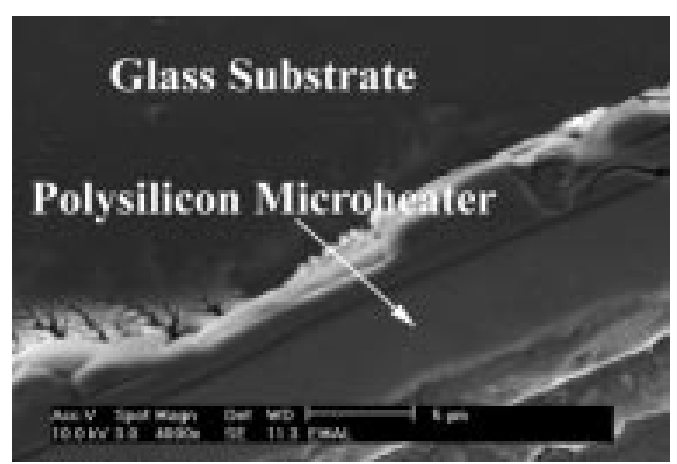

(b)

Fig. 4. The enlarge view of SEM micrographs of localized aluminum-glass bonding and localized aluminum/silicon-glass bonding interfaces after forcefully broken (a) aluminum is stripped then transferred onto the glass substrate (b) both aluminum and polysilicon microheater are stripped then transferred onto the glass substrate.

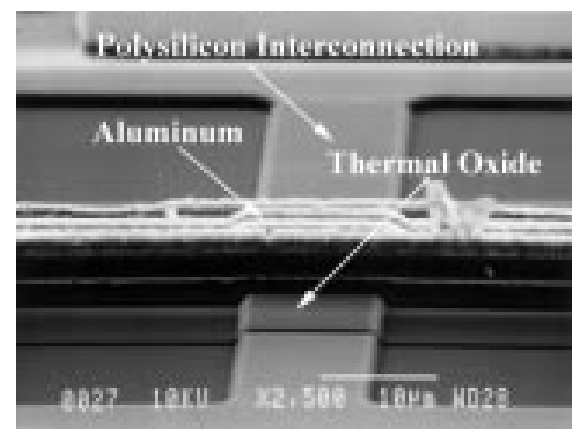

Fig. 5. A close view SEM on the silicon substrate before reflowing. The step up of aluminum/silicon solder is caused by the underneath polysilicon interconnect line.

This indicates that aluminum/silicon-glass bond can also provide a strong bond between the aluminum/silicon and glass interface.

One of the advantages in using localized solder bonding to packaging devices is that there is no need for a planarization process. In [9], we reported indium solder reflow to overcome the surface topography which is created by electrical interconnects. The principle can also be applied in aluminum/silicon-glass bonding system. Fig. 5 shows a SEM photograph of the microheater and bond region after aluminum is deposited. A good surface coverage after the localized heating to reflow the aluminum/silicon solder can be seen in Fig. 6(a). In addition, $2 \mu \mathrm{m}$ spacing between two parallel 


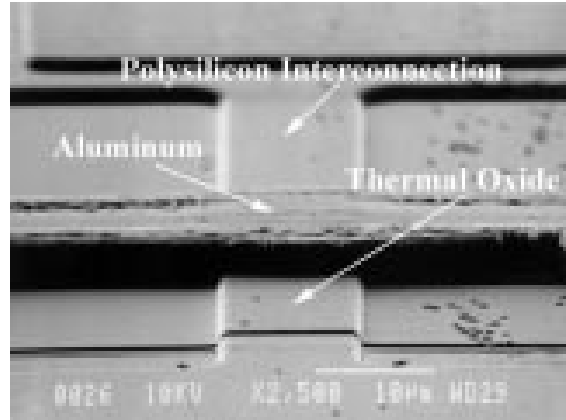

(a)

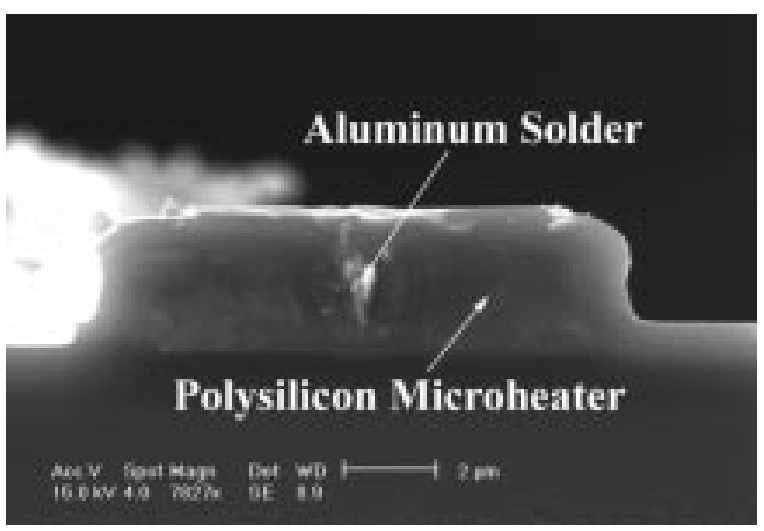

(b)

Fig. 6. Close-up SEM of the polysilicon microheater after reflowing. Very good step coverage is achieved (a) top view and (b) cross-sectional view.

polysilicon lines is filled up by solder as shown in the cross sectional SEM of the microheater in Fig. 6(b).

\section{B. Hermetic Packaging and Testing}

The package has been subjected to two kinds of tests: 1) gross leak check in IPA (Isopropanol Alcohol), and 2) accelerated test in an autoclave [20] under $3 \mathrm{~atm}, 100 \% \mathrm{RH}$, and $128^{\circ} \mathrm{C}$. Because IPA has better wetability than water, it can more easily penetrate small openings, and is more suitable for gross leak check. Based on visual observation and as evident from the contrast difference that is due to different refraction indexes from air to IPA in these observations, it is shown that IPA cannot penetrate the aluminum/silicon-to-glass bond region. The gross IPA leak check is useful in screening devices for the accelerated test.

Accelerated test is then performed in an autoclave on devices that passed the IPA immersion test. Hermeticity was tested using interdigited patterns that operate as dew point sensors. Interdigited dew point sensor has been previuosly used for lifetime testing of hermetic packages [11], [21]. The operating principle is based on large resistance change between closely spaced interdigited electrodes of the sensor. Once moisture condenses on the whole surface of electrodes, the capacitance between these electrodes will increase because the relative dielectric constant changes from dry air $\left(\varepsilon_{r}=1\right)$ to water $\left(\varepsilon_{r}=80\right)$. Moreover, water has higher electrical conductivity than dry air. Therefore, the total impedance of the dew point sensor will decrease when moisture enters and condenses inside the package. Fig. 7 shows the drastic impedance and phase change of the dew point sensor due to moisture penetration and condensation after a 30 -h test.

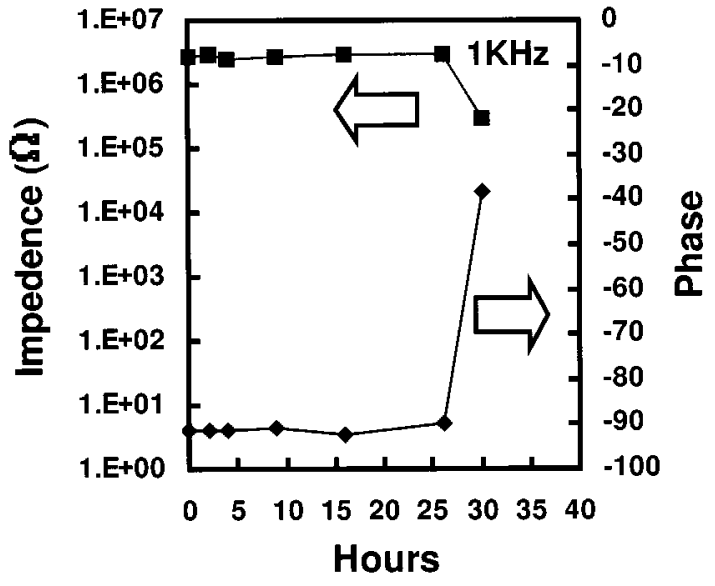

Fig. 7. Results from the autoclave test. After $30 \mathrm{~h}$, a drastic change is measured.

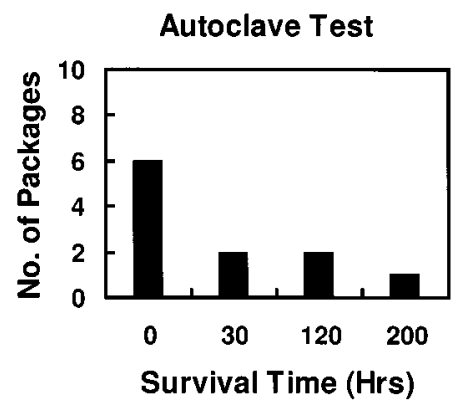

Fig. 8. Statistical test results of autoclave test. These devices had all passed the IPA test.

A total of 11 packages are tested in the autoclave as illustrated in Fig. 8. All of these packages are fabricated under $0.1 \mathrm{MPa}$ contact pressure and $700{ }^{\circ} \mathrm{C}$ bonding temperature for $5 \mathrm{~min}$. Six of these packages failed almost immediately after insertion into the autoclave, two failed after $30 \mathrm{~h}$, two failed after $120 \mathrm{~h}$, and one failed after $200 \mathrm{~h}$ in the autoclave. In order to determine failure mechanisms, the glass package was forcefully separated from the silicon substrate and the bonding region was examined. Fig. 9(a) and (b) show the device and the cap substrates, respectively. It is observed that in many regions, either the glass or the microheater with its underneath silicon substrate is stripped and attached onto the other substrate, indicating a strong bond. However, when the bonding process is not conducted correctly as shown on the right bottom corner of Fig. 9(a) and the enlarged view in Fig. 10, moisture can diffuse into the package. In the package that lasted more than 200 hours in the autoclave, the unbonded region is much smaller, and almost undetectable.

Since the bonding quality of aluminum/silicon-to-glass is determined by the interface reaction of aluminum-to-glass which depends on bonding temperature and time, another 11 packages are refabricated and subjected to the autoclave test. In this second run, all eleven new packages are produced by increasing the bonding time and contact pressure, which are changed from $5 \mathrm{~min}$ to $7.5 \mathrm{~min}$ and from $0.1 \mathrm{MPa}$ to $0.2 \mathrm{MPa}$, respectively. Increasing the contact pressure and bonding time ensures that aluminum solder intimately contacts and totally reacts with glass. Fig. 11 shows the autoclave test results. Only one package failed immediately after insertion into the autoclave, three failed after 


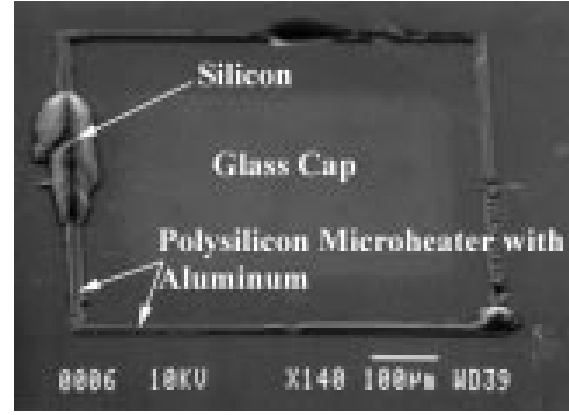

(a)

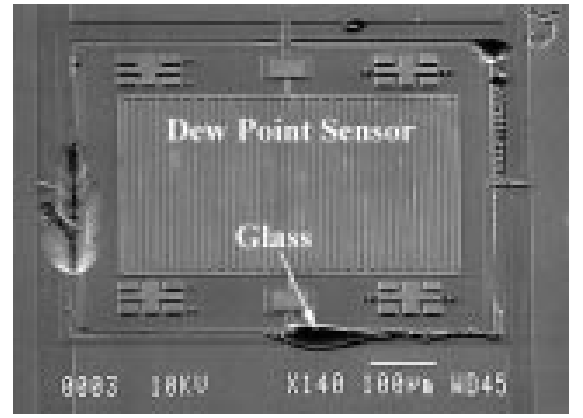

(b)

Fig. 9. SEM micrographs of the device substrate and glass cap after breaking the bonding interface (a) glass is torn apart and transferred onto the device substrate and (b) the polysilicon micorheater with aluminum solder is removed from silicon and attached to the glass cap.

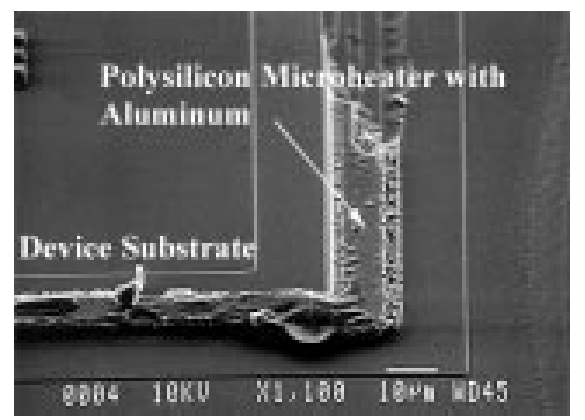

Fig. 10. Enlarged view SEM micrograph on the device substrate. There is some area which has weak formation of aluminum/silicon-to-glass bond and is the leakage path for moisture.

$10 \mathrm{~h}$, three failed after $30 \mathrm{~h}$, one failed after $80 \mathrm{~h}$ and three were damaged after $450 \mathrm{~h}$ when the autoclave chamber suddenly broke down. Even though significant improvement has been obtained, it is evident that some devices still fail prematurely. Because raising the bonding temperature instead of increasing the bonding time can also improve bonding quality, there are still many ways to improve bonding yield and quality.

\section{DISCUSSION}

According to the broken interface of glass and silicon substrate, the bonding strength of glass/silicon-glass is higher than the failure strength of pyrex glass or silicon which is above $10 \mathrm{MPa}$ [22] which is very suitable for micropackaging. In order to understand the bonding mechanism which creates such high bonding strength, aluminum-glass and aluminum/silicon-glass system are investigated by measuring the activation energy $(E a)$ in the temperature region above the eutectic point, $577^{\circ} \mathrm{C}$, of

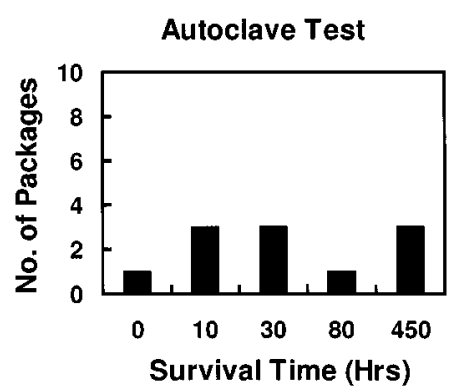

Fig. 11. Statistical autoclave test results of another 11 packages produced by increasing bonding time and pressure. These devices had passed IPA leakage test.

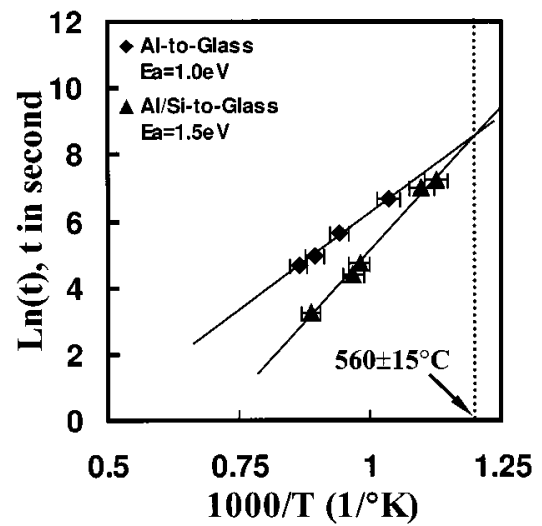

Fig. 12. Experimental results of bonding time for a given fracture morphology versus bonding temperature in both cases of aluminum-to-glass and aluminum/polysilicon-to-glass bondings. Two curve fitting lines are intersected at $560 \pm 15{ }^{\circ} \mathrm{C}$ which is very close to the eutectic point of aluminum-silicon binary alloy.

silicon-aluminum alloy, respectively. Fig. 12 shows the measurement results where $t$ is the bonding time to a given fracture morphology and $T$ is temperature in Kelvin. The interface bonding reaction can be described in Arhennius relationship

$$
\ln (\mathrm{t})=E a / K *(1 / T)+\mathrm{C}
$$

where

C constant;

$K \quad$ Boltzmann constant;

$E a \quad 1.0 \mathrm{eV}$ and $1.5 \mathrm{eV}$ for the aluminum-glass and aluminum/silicon-glass system, respectively.

The aluminum-glass results are close to the report by Prabriputaloong et al. [17] for the activation of aluminum to vitreous glass and quartz which are $0.73 \pm 0.07 \mathrm{eV}$ and $1.17 \pm 0.12 \mathrm{eV}$, respectively, and the report by Brendel et al. [16] result for the reaction of aluminum to a-SiOx $(0.98 \mathrm{eV})$. Both of them proposed that aluminum atoms would replace the silicon atom in the coordination of silicon dioxide to form aluminum oxide. In order to examine this reaction in the localized aluminum-glass bonding experiments, the sample in Fig. 4(a) is placed into type-A [23] aluminum etchant for $10 \mathrm{~min}$ to remove aluminum and Fig. 13(a) shows the result. A porous layer on top of the glass substrate is observed. The sample is then dipped into tetramethyl ammonium hydroxide (TMAH) [24] solution for $20 \mathrm{~min}$ to remove silicon precipitate. Fig. 13(b) shows the etching result and the remaining material is believed 


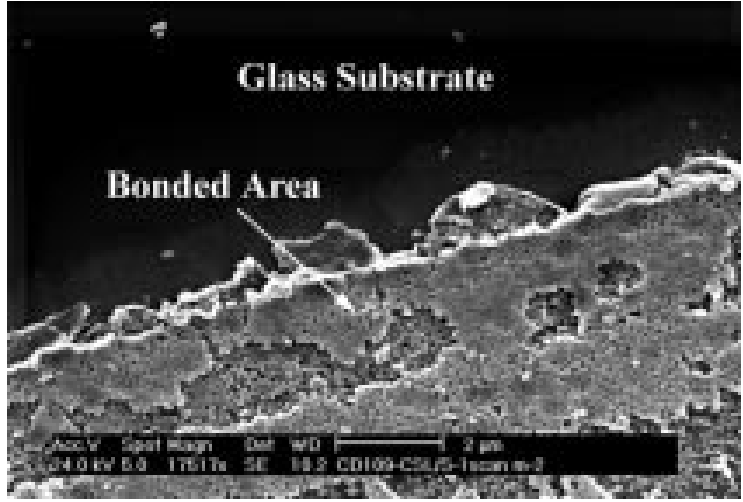

(a)

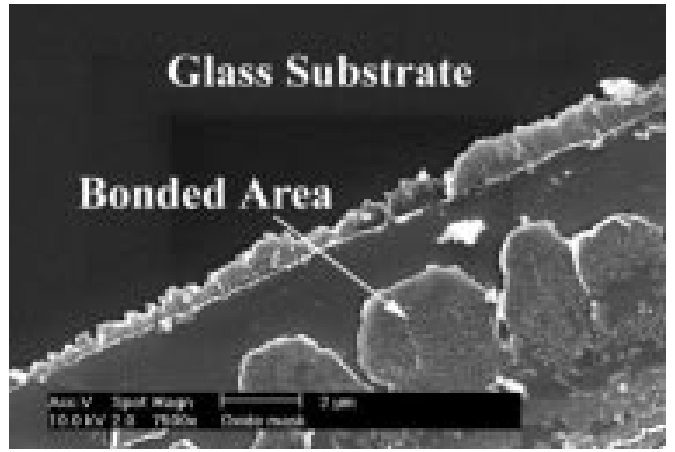

(b)

Fig. 13. Close view of SEMs (a) after 10 min etching by dipping the sample in Fig. 3(a) into aluminum type A etchant to remove aluminum. It shows a porous layer is on top of glass substrate. (b) The porous layer is then dipping into TMAH solution to remove silicon precipitate. A residual thin layer is believed to be aluminum oxide which will not be attacked by TMAH solution.

to be aluminum oxide. A similar phenomenon is also found in the aluminum/silicon-glass bond. These activation energy measurements and post-bonding examinations suggest that the aluminum-glass and aluminum/silicon-glass bonds result from the formation of aluminum oxide and silicon precipitate.

Fig. 12 also reveals several important phenomena. First, the two experimental curves meet at a temperature of $560 \pm 15^{\circ} \mathrm{C}$ which is very close to the eutectic point of aluminum-silicon binary system. This indicates that both bonding systems require similar time to complete the bonding process at the aluminum-silicon eutectic temperature. Second, under the same bonding temperature, the aluminum/silicon-glass system requires less time for bonding as compared with the aluminum-glass system once the bonding temperature is above the eutectic temperature. It is due to silicon atoms dissolving into aluminum and forming silicon aluminum alloy which has lower liquid phase temperature and could speed up the bonding process in terms of assisting oxygen diffusion. Although it has been suggested that oxygen atoms could easily diffuse in liquid aluminum and help the aluminum-glass bonding process, further studies are required to investigate this phenomenon.

Although the unbonded region can be reduced by increasing either the bonding time or temperature as characterized in the Arhennius relationship, it is necessary to consider thermal stress effects induced by different thermal expansion coefficients between aluminum and glass when increasing the bonding temperature. To test this, another 11 packages are fabricated under

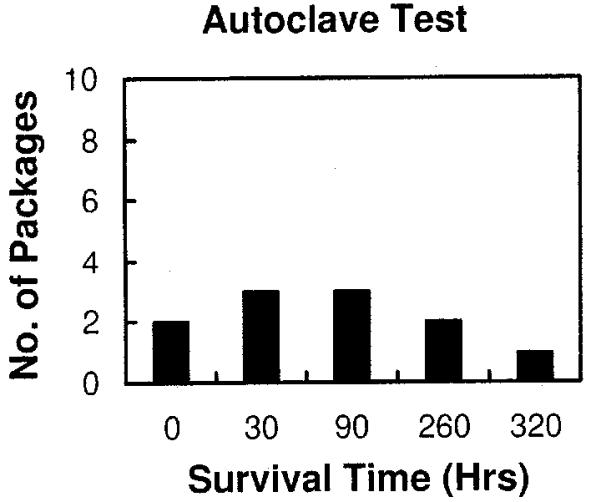

Fig. 14. Statistical autoclave test results of another 11 packages produced by increasing bonding temperature to $850^{\circ} \mathrm{C}$ for $2 \mathrm{~min}$.

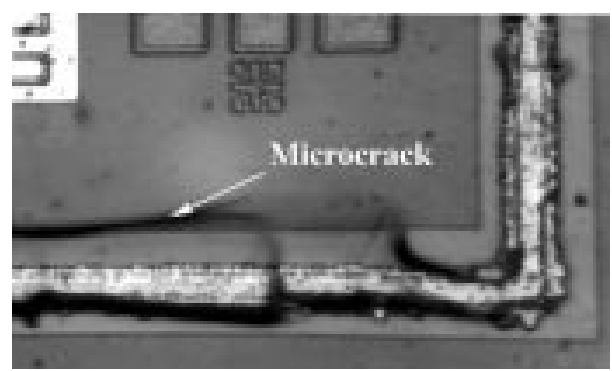

Fig. 15. Optical photograph of the hermetic package fabricated at $850^{\circ} \mathrm{C}$ for 2 min showing microcrack formation on the glass capsule due to the thermal stress effects.

$\sim 850{ }^{\circ} \mathrm{C}$ bonding temperature for $2 \mathrm{~min}$ and inserted into the autoclave. In this test, 8 of 11 devices survived less then $120 \mathrm{~h}$ as shown in Fig. 14. No unbonded region was observed after breaking the bonding interface. The failure mechanism is identified to be due to microcracks formed in the glass cap during the bonding process as shown in Fig. 15, which is the optical photograph of the hermetic package. Therefore, a lower bonding temperature or cooling rate is recommended for the packaging.

Packaging test results can be statistically described by a Weibull distribution function where:

$$
F(t)=1-\operatorname{Exp}\left[-(t / \lambda)^{\beta}\right] .
$$

$F(t)$ is the cumulative distribution function (cdf), $t$ is time, $\beta$ is shape factor and $\lambda$ is characteristic lifetime that is the mean time to failure (MTTF). Weibull distribution is a common statistical theory to calculate the mean time to failure (MTTF) of packages [25]. According to the 11 package tests of the second set which are fabricated under improved conditions, $700{ }^{\circ} \mathrm{C}$ and $0.2 \mathrm{MPa}$ for $7.5 \mathrm{~min}$, it is found that the MTTF of total 11 glass-silicon packages is about 170 hours and the shape factor is about 0.66 . The lifetime is higher than published MTTF of epoxy-molded packages which is about $8 \mathrm{~h}$ only under $1 \mathrm{~atm}, 100 \% \mathrm{RH}$, and $130^{\circ} \mathrm{C}$ environment [26]. The shape factor less than 1 indicates some defects that cause device failure already exist during the package fabrication like the unbonded region or unobservable microcracks. Since MTTF is estimated by a statistical method, producing more test dice will provide more accurate MTTF and help us further understand the reliability of this packaging. 


\section{CONCLUSION}

Aluminum/silicon-to-glass bonding based on localized heating technique has been successfully developed and applied to hermetic packaging with an inter-digited pattern style of dew point sensor. The surface step created by the electrical interconnect line can be planarized by reflowing aluminum/silicon solder without affecting the performance of the packaged sensor. Strong aluminum-glass and aluminum/silicon-glass bonds achieved by the localized bonding process have been characterized by the activation energy measurement. The measured activation energy of $1.0 \mathrm{eV}$ for the aluminum-glass system, is very close to that measured by the globalized heating and bonding schemes. The bonding mechanism relies on the formation of silicon precipitate and aluminum oxide combination which can provide more than $10 \mathrm{MPa}$ bonding strength and good hermeticity. Moreover, adding silicon to the aluminum-glass system will speed up the bonding process by reducing the required bonding time. An autoclave testing shows some of hermetic packages can survive more than $450 \mathrm{~h}$ at $3 \mathrm{~atm}, 100 \% \mathrm{RH}$ and $128^{\circ} \mathrm{C}$. Nonuniform bonding or microcracks have been identified as the main failure mechanisms to hermetic seal with lifetime less than $200 \mathrm{~h}$. Experimental results also indicate bonding quality can be improved by increasing bonding time and applied pressure to make sure intimate contact between aluminum and glass.

\section{ACKNOWLEDGMENT}

The authors would like to thank Prof. Nguyen at the University of Michigan, Ann Arbor, for valuable discussions.

\section{REFERENCES}

[1] C. P. Wang, "Recent advance in hermetic equivalent flip-chip hybrid IC packaging of microelectronics," Mater. Chem. Phys., vol. 42, pp. 25-30, 1995.

[2] C. T.-C. Nguyen, "Micromachining technologies for miniaturized communication devices," Proc. SPIE, vol. 3514, pp. 24-38, 1998.

[3] K. Najafi, "Silicon micromachining technologies: Future needs and challenges," Proc. SPIE, vol. 2879, pp. 206-215, 1996.

[4] S. T. Chou and F. M. Erdamann, "An on-chip hermetic package technology for micromechanical devices," in Proc. Tech. Dig. 1998 Solid State Sensor and Actuator Workshop, Hilton Head, SC, June 1998, pp. 229-232.

[5] D. Ando, K. Oishi, T. Nakamura, and S. Umeda, "Glass direct bonding technology for hermetic seal package," in Proc. IEEE MicroElectro Mechanical Systems, 1997, pp. 186-190.

[6] B. Shivkuma and C. J. Kim, "Microrivets for MEMS packaging: Concept, fanrication, and strength testing," J. Microelectromech. Syst., vol. 6, pp. 217-225, 1997.

[7] M. B. Cohn, K. F. Bohringer, J. M. Noworolski, A. Singh, C. G. Keller, K. Y. Goldberg, and R. T. Howe, "Microassembly technologies for MEMS," Proc. SPIE, vol. 3512, pp. 2-16, 1998.

[8] Y. T. Cheng, L. Lin, and K. Najafi, "Localized silicon fusion and eutectic bonding for MEMS fabrication and packaging," in Proc. Tech. Dig. 1998 Solid State Sensor and Actuator Workshop, Hilton Head, SC, 1998, pp. 233-236.

[9] - "Localized bonding with PSG or indium solder as intermediate layer," in Proc. IEEE MicroElectro Mechanical Systems, 1999, pp. 285-289.
[10] G. H. He, L. Lin, and Y. T. Cheng, "Localized CVD bonding for MEMS packaging," in Proc. Tech. Dig. 10th Int. Conference on Solid State Sensors and Actuators, Transducers 99, Sendia, Japan, 1999, pp. $1312-1315$.

[11] B. Ziaie, J. A. Von Arx, M. R. Dokmeci, and K. Najafi, "A hermetic glass-silicon micropackage with high-density on-chip feedthroughs for sensors and actuators," J. Microelectromech. Syst., vol. 5, pp. 166-179, 1996.

[12] C. M. Ryu, U. Koelle, S. R. Johnson, P. Dowd, R. Turpin, P. Kelkar, and Y.-H. Zhang, "Optical interconnects for high-speed data links," Proc. SPIE, vol. 3631, pp. 10-17, 1999.

[13] G. Humpton and D. M. Jacobson, "Principles of soldering and brazing," in Proc. ASM Int., 1993, pp. 241-244.

[14] S. Angad, A. Horsely, M. B. Cohn, A. P. Pisano, and R. T. Howe, "Batch transfer of microstructures using flip-chip solder bonding," J. Microelectromech. Syst., vol. 8, pp. 27-33, 1999.

[15] W. H. Ko, J. T. Suminto, and G. J. Yeh, "Bonding techniques for microsensors," in Micromachining and Micropackaging for Transducers. New York: Elsevier Science, 1985.

[16] R. Brendel and R. Hezel, "Infrared observation of thermally activated oxide reduction within $\mathrm{Al} / \mathrm{SiOx} / \mathrm{Si}$ tunnel diodes," J. Appl. Phys., vol. 71, pp. 4377-4381, 1992.

[17] K. Prabriputaloong and M. R. Piggott, "The reaction between silica and aluminum," J. Electrochem. Soc., pp. 430-434, 1974.

[18] C. M. Osburn and N. J. Chou, "Accelerated dielectric breakdown of silicon dioxide films," J. Electrochem. Soc., pp. 1377-1384, 1973.

[19] F. Dadabhai, F. Gaspari, S. Zukotynski, and C. Bland, "Reduction of silicon dioxide by aluminum in metal-oxide-semiconductor structures," J. Appl. Phys., vol. 80, pp. 6505-6509, 1996.

[20] W. J. McGarvey, "Autoclave vs $85^{\circ} \mathrm{C} / 85 \%$ RH testing," in Proc. Int. Reliablity Physics Symp., 1979, pp. 136-142.

[21] M. G. Kovac, D. Chleck, and P. Goodman, "A new moisture sensor for in-site monitoring of sealed package," in Proc. Int. Reliablity Physics Symp., 1977, pp. 85-91.

[22] R. W. Bower, M. S. Ismail, and B. E. Roberds, "Low temperature $\mathrm{Si}_{3} \mathrm{~N}_{4}$ direct bonding," Appl. Phys. Lett., vol. 62, pp. 3485-3487, 1993.

[23] K. R. Williams and R. S. Muller, "Etch rate for micromaching processing," J. Microelectromech. Syst., vol. 5, pp. 256-269, 1996.

[24] U. Schnakenberg, W. Benecke, and P. Lange, "TMAH etchant for silicon micromachining," in Proc. Int. Conference on Solid State Sensors and Actuators, Transducers 91, 1991, pp. 815-818.

[25] R. R. Tummala, E. J. Rymaszewski, and A. G. Klopfenstein, Microelectronics Packaging Handbook. New York: Chapman and Hill, 1997, pt. I, pp. 407-423.

[26] R. R. Tummala, E. J. Rymaszewski, and A. G. Klopfenstein, Microelectronics Packaging Handbook. New York: Chapman and Hill, 1997, pt. I, p. 918.

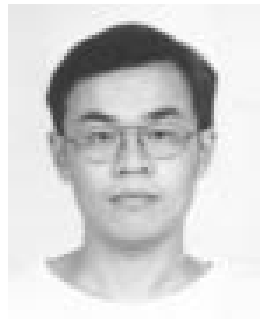

Yu-Ting Cheng was born in Taiwan, Republic of China. He received the B.S. and M.S. degrees in materials science and engineering, National Tsing Hua University, Hsinchu, Taiwan, in 1991 and 1993, the M.S. degree in the field of materials science and engineering from Carnegie Mellon University, Pittsburgh, PA, in 1996, and the Ph.D. degree in electrical engineering from the University of Michigan, Ann Arbor, in 2000. His thesis is the development of a novel vacuum packaging technique for MEMS applications.

His research interests include the fundamental study of materials for MEMS applications, micropackaging, and new hybrid micromachining fabrication of microstructures, microsensors and microactuators. He is currently working for IBM Thomas J. Watson Research Center, Yorktown Heights, NY, as a Research Staff Member and involved in several SOP (systems on packages) projects.

Dr. Cheng is a member of Phi Tau Phi. 


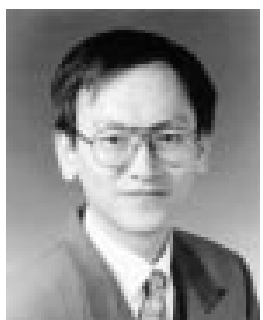

Liwei Lin received the M.S. and Ph.D. degrees in mechanical engineering from the University of California, Berkeley, in 1991 and 1993, respectively.

He joined BEI Electronics, Inc., and from 1993 to 1994 , he was involved in research and development of microsensors. From 1994 to 1996, he was an Associate Professor in the Institute of Applied Mechanics, National Taiwan University, Taiwan. From 1996 to 1999, he was an Assistant Professor at the Mechanical Engineering and Applied Mechanics Department at the University of Michigan. Since 1999, he has been an Assistant Professor at Mechanical Engineering Department and Co-Director at Berkeley Sensor and Actuator Center, NSF/Industry/University Research Cooperative Center, at University of California at Berkeley. His research interests are in microelectromechanical systems, including design, modeling and fabrication of microstructures, microsensors, and microactuators.

Dr. Lin is the recipient of the 1998 NSF CAREER Award for research in MEMS Packaging and the 1999 ASME Journal of Heat Transfer Best Paper Award for his work on micro scale bubble formation. He led the effort in establishing the MEMS subdivision in ASME and is currently serving as the Vice Chairman of the Executive Committee for the MEMS subdivision. He holds six U.S. patents in the area of MEMS.

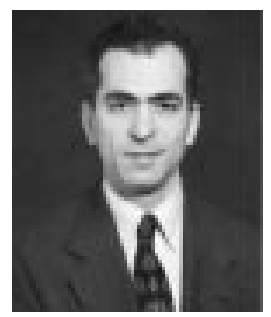

Khalil Najafi (S'84-M'86-SM'97-F'00) was born in 1958. He received the B.S., M.S., and Ph.D. degrees in 1980, 1981, and 1986, respectively, all in electrical engineering from the Department of Electrical Engineering and Computer Science, University of Michigan, Ann Arbor.

From 1986 to 1988 , he was employed as a Research Fellow, from 1988 to 1990, as an Assistant Research Scientist, from 1990 to 1993, as an Assistant Professor, from 1993 to 1998, as an Associate Professor, and since September 1998, as a Professor, and the Director of the Solid-State Electronics Laboratory, Department of Electrical Engineering and Computer Science, University of Michigan. His research interests include: micromachining technologies, solid-state micromachined sensors, actuators, and MEMS; analog integrated circuits; implantable biomedical microsystems; hermetic micropackaging; and low-power wireless sensing/actuating systems.

Dr. Najafi was awarded a National Science Foundation Young Investigator Award from 1992 to 1997, was the recipient of the Beatrice Winner Award for Editorial Excellence at the 1986 International Solid-State Circuits Conference, of the Paul Rappaport Award for coauthoring the Best Paper published in the IEEE TRansactions on Electron Devices, and of the Best Paper Award at ISSCC 1999. In 1994, he received the University of Michigan's "Henry Russel Award" for outstanding achievement and scholarship, and was selected as the "Professor of the Year" in 1993. In 1998, he was named the Arthur F. Thurnau Professor for outstanding contributions to teaching and research, and received the College of Engineering's Research Excellence Award. He has been active in the field of solid-state sensors and actuators for more than 18 years, and has been involved in several conferences and workshops dealing with solid-state sensors and actuators, including the International Conference on Solid-State Sensors and Actuators, the Hilton-Head Solid-State Sensors and Actuators Workshop, and the IEEE/ASME Microelectromechanical Systems (MEMS) Workshop. He is the Editor for Solid-State Sensors for IEEE TRAnsactions on Electron DEvices, Associate Editor for IEEE Transactions on Biomedical EngINEERING, Associate Editor for IEEE Journal OF SOlID-STATE CIRCUITS, and an Associate Editor for the Journal of Micromechanics and Microengineering, Institute of Physics Publishing. 